
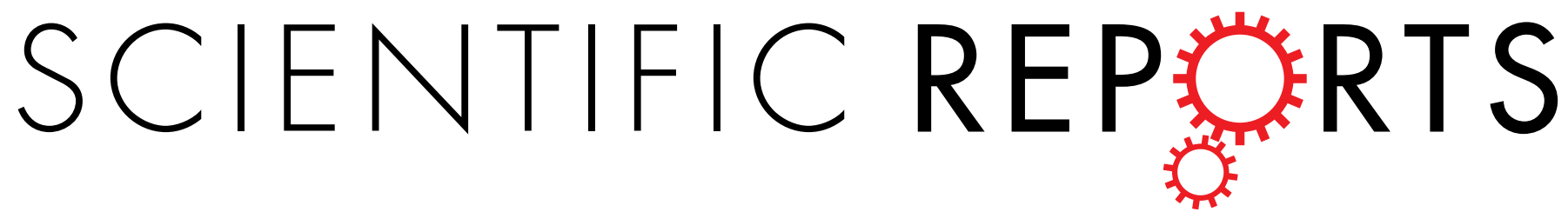

\title{
OPEN Anaerobic decomposition of humic substances by Clostridium from the deep subsurface
}

Received: 21 August 2015

Accepted: 02 December 2015

Published: 08 January 2016

\author{
Akio Ueno ${ }^{1}$, Satoru Shimizu ${ }^{1}$, Shuji Tamamura ${ }^{1}$, Hidetoshi Okuyama ${ }^{2}$, Takeshi Naganuma ${ }^{3}$ \& \\ Katsuhiko Kaneko ${ }^{1}$
}

Decomposition of humic substances (HSs) is a slow and cryptic but non-negligible component of carbon cycling in sediments. Aerobic decomposition of HSs by microorganisms in the surface environment has been well documented; however, the mechanism of anaerobic microbial decomposition of HSs is not completely understood. Moreover, no microorganisms capable of anaerobic decomposition of HSs have been isolated. Here, we report the anaerobic decomposition of humic acids (HAs) by the anaerobic bacterium Clostridium sp. HSAI-1 isolated from the deep terrestrial subsurface. The use of ${ }^{14} \mathrm{C}$-labelled polycatechol as an $\mathrm{HA}$ analogue demonstrated that the bacterium decomposed this substance up to $7.4 \%$ over 14 days. The decomposition of commercial and natural HAs by the bacterium yielded lower molecular mass fractions, as determined using high-performance size-exclusion chromatography. Fourier transform infrared spectroscopy revealed the removal of carboxyl groups and polysacchariderelated substances, as well as the generation of aliphatic components, amide and aromatic groups. Therefore, our results suggest that Clostridium sp. HSAI-1 anaerobically decomposes and transforms HSs. This study improves our understanding of the anaerobic decomposition of HSs in the hidden carbon cycling in the Earth's subsurface.

The carbon mass in the Earth's crust, including sediments and sedimentary rock, is estimated to be $7.78-9.00 \times 10^{22} \mathrm{~g} \mathrm{C}$, which is second only to the carbon pool in the mantle ${ }^{1}$. Although the majority of crustal carbon is inorganic and lies in limestone, the organic carbon mass is estimated to be $1.25 \times 10^{22} \mathrm{~g} \mathrm{C}^{1}$, corresponding to approximately one sixth of the crustal carbon. Measurements of contemporary sediments indicate that refractory fractions, or humic substances (HSs), account for $40-90 \%$ of the total organic carbon in sediments ${ }^{2}$.

To reveal the global carbon cycle through the microbial decomposition of HSs in the sedimentary rock systems, we focused on the anaerobic decomposition of HS. This study reports the anaerobic decomposition of HSs by a single bacterium isolated from the deep subsurface, rather than by a microbial consortium. The bacterium decomposed both commercial and natural humic acids (HAs) extracted from the deep subsurface diatomite layer in the northernmost region of Hokkaido, Japan ${ }^{3}$. Given that the bacterium and HAs were collected from subsurface environments, anaerobic HS decomposition may occur widely in situ. Most of the decomposition products were found in lower molecular mass fractions as expected.

\section{Results}

Isolation and growth properties of an HS-decomposing bacterium. We isolated a strictly anaerobic HS-decomposing bacterium following enrichment cultivation in media containing commercial HSs (Aldrich HAs). The $16 \mathrm{~S}$ rRNA gene sequence of the isolate was most closely related to that of Clostridium puniceum DSM $2619^{\mathrm{T}}$ (98.9\% similarity) (Supplementary Fig. 1); therefore, the isolate was designated Clostridium sp. strain HSAI-1.

The growth of strain HSAI-1 was monitored based on the increase in cell numbers in media containing Aldrich HAs or naturally occurring HAs from the Koetoi diatomite layer with or without $0.5 \%$ glucose (Supplementary Table 1). The initial cell density in each experiment was set at $1.2-1.5 \times 10^{7}$ cells $\mathrm{mL}^{-1}$. A 10 -fold increase occurred

\footnotetext{
${ }^{1}$ Horonobe Research Institute for the Subsurface Environment, Northern Advancement Centre for Science and Technology, 5-3, Sakae-machi, Horonobe-cho, Teshio-gun, Hokkaido 098-3221, Japan. ${ }^{2}$ Graduate School of Environmental Earth Science, Hokkaido University, Sapporo, Hokkaido 060-0810, Japan. ${ }^{3}$ Graduate School of Biosphere Science, Hiroshima University, Higashi-Hiroshima 739-8528, Japan. Correspondence and requests for materials should be addressed to A.U. (email: akio.veno@h-rise.jp)
} 


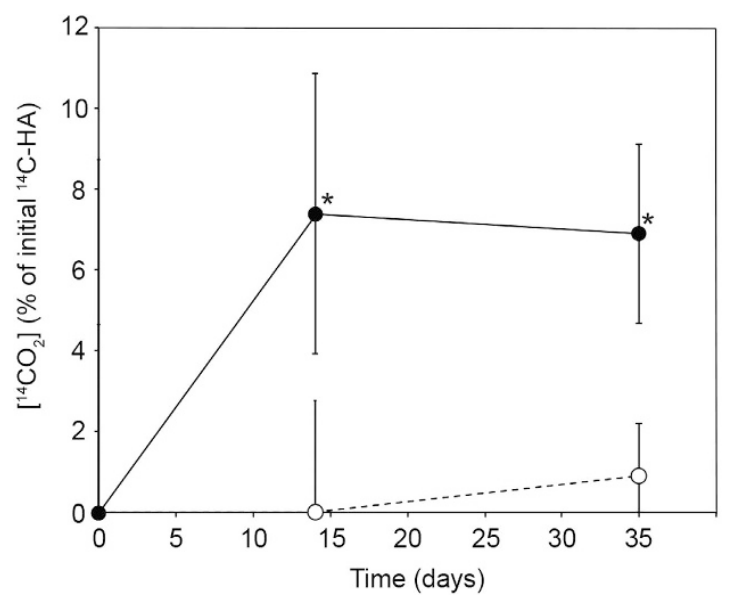

Figure 1. ${ }^{14} \mathrm{CO}_{2}$ evolution in an anaerobic culture of Clostridium sp. strain HSAI-1. The ${ }^{14} \mathrm{CO}_{2}$ in the headspace gas was measured via liquid scintillation counting of inoculated cultures (filled circles). Uninoculated control cultures (open circles) yielded little or no ${ }^{14} \mathrm{CO}_{2}$. The data points are the mean values of triplicate samples \pm standard deviations. ${ }^{\star} P<0.05$ was considered significant in Student's $t$-test.

\begin{tabular}{|l|c|c|c|}
\hline \multirow{2}{*}{ Sample } & \multicolumn{3}{|c|}{$\%$ of ${ }^{14} \mathrm{C}$ in: } \\
\cline { 2 - 4 } & ${ }^{14} \mathrm{CO}_{2}$ & Soluble & Insoluble/cell-bound \\
\hline Control & $0.7 \pm 1.3$ & $58.5 \pm 6.2$ & $40.8 \pm 1.3$ \\
\hline Strain HSAI-1 & $6.6 \pm 2.2$ & $43.0 \pm 2.4$ & $50.4 \pm 0.7$ \\
\hline
\end{tabular}

Table 1. Mass balance of radioactive carbon. Percentage of ${ }^{14} \mathrm{C}$ in each fraction after treatment of a synthetic ${ }^{14} \mathrm{C}$-labelled polycatechol analogous to humic acids with Clostridium sp. strain HSAI-1. The presented values were obtained at the end of the incubation period (49 days) and are the mean \pm standard deviation $(n=3)$.

in 8 days in cultures supplemented with glucose, whereas only a small increase was observed when HAs were the sole carbon source. In subsequent experiments, cultures were supplemented with $0.5 \%$ glucose.

Decomposition of a ${ }^{14} \mathrm{C}$-labelled $\mathrm{HA}$ analogue. The release of ${ }^{14} \mathrm{CO}_{2}$ from ${ }^{14} \mathrm{C}$-labelled polycatechol, an $\mathrm{HA}$ analogue, was monitored as an index of bacterial HA decomposition (Fig. 1). Maximal ${ }^{14} \mathrm{CO}_{2}$ evolution corresponding to $7.4 \pm 3.5 \%$ of the exogenous ${ }^{14} \mathrm{C}$-HA was observed in cultures containing strain HSAI- 1 in the first 14 days, compared with little or no ${ }^{14} \mathrm{CO}_{2}$ evolution in the uninoculated control experiments $(P<0.05)$. The rate of ${ }^{14} \mathrm{CO}_{2}$ evolution slowed thereafter, likely due to the increased recalcitrance of polycatechol to biodegradation. The total balance of ${ }^{14} \mathrm{C}$ was calculated at the end of this experiment (Table 1). In the uninoculated control experiments, a small amount of ${ }^{14} \mathrm{CO}_{2}(0.7 \%)$ was detected, which was attributed to spontaneous release, and $58.5 \%$ soluble and $40.8 \%$ insoluble fractions were retrieved. Conversely, experiments inoculated with HSAI- 1 yielded $6.6 \%{ }^{14} \mathrm{CO}_{2}$ (approximately 10 -fold the amount obtained through "spontaneous" release); in this case, $43.0 \%$ soluble and $50.4 \%$ insoluble fractions were retrieved. The proportion of insoluble fractions in the experiments with HSAI-1 was higher than those in the uninoculated controls.

Instrumental analyses of HAs. Using high-performance size-exclusion chromatography (HPSEC), we demonstrated the decomposition of HAs during a 28-day incubation with the Clostridium sp. strain HSAI-1. HA decomposition was confirmed in terms of its amounts and molecular masses. While decreased peaks indicate decreased HA levels, delays in retention times reflect reductions in molecular mass. Major chromatographic peaks at retention times of 7.3-8.3 min, which corresponded to molecular masses of approximately $2-3 \mathrm{kDa}$, indicated reductions in molecular mass (Fig. 2 and Supplementary Fig. 4). The mean values $( \pm S D)$ of the molecular masses at the peaks were calculated and are shown in Table 2 . At day 0 , significant differences were not observed between the uninoculated control and the HSAI-1 inoculated culture (2790.1 \pm 15.5 vs. $2801.4 \pm 12.7 \mathrm{Da}$ for Aldrich HAs, $P=0.242 ; 3317.9 \pm 0.0$ vs. $3286.2 \pm 31.7$ Da for Koetoi HAs, $P=0.056$ ), whereas a significant difference was observed at 28 days $(2887.3 \pm 12.9$ vs. $2673.1 \pm 76.8 \mathrm{Da}$ for Aldrich HAs, $P<0.001 ; 3229.6 \pm 14.0$ vs. $2824.4 \pm 51.8 \mathrm{Da}$ for Koetoi HAs, $P<0.001$ ) (Table 2). The reductions were 214.2 Da for the commercial Aldrich HAs and 405.2 Da for the natural Koetoi HAs. Similar shifts in peak height and retention time were reproduced with a well-known aerobic HA-degrading actinomycete, Streptomyces viridosporus (ATCC 39115; Supplementary Fig. 3$)^{4}$. To our surprise, a conspicuous peak at $7.3 \mathrm{~min}$ in the Koetoi HAs increased in both its amount and molecular mass (Fig. 2, lower right); the molecular mass of the peak exceeded $50 \mathrm{kDa}$, as estimated based on the size exclusion limit of the column.

Through Fourier transform infrared (FT-IR) analysis, we demonstrated that the bacterial HA decomposition induced structural changes in HAs (Fig. 3 and Supplementary Table 2). Several notable changes can be summarised as follows: 1) the disappearance of two absorption bands in Aldrich HAs and three bands in Koetoi HAs, specifically, 


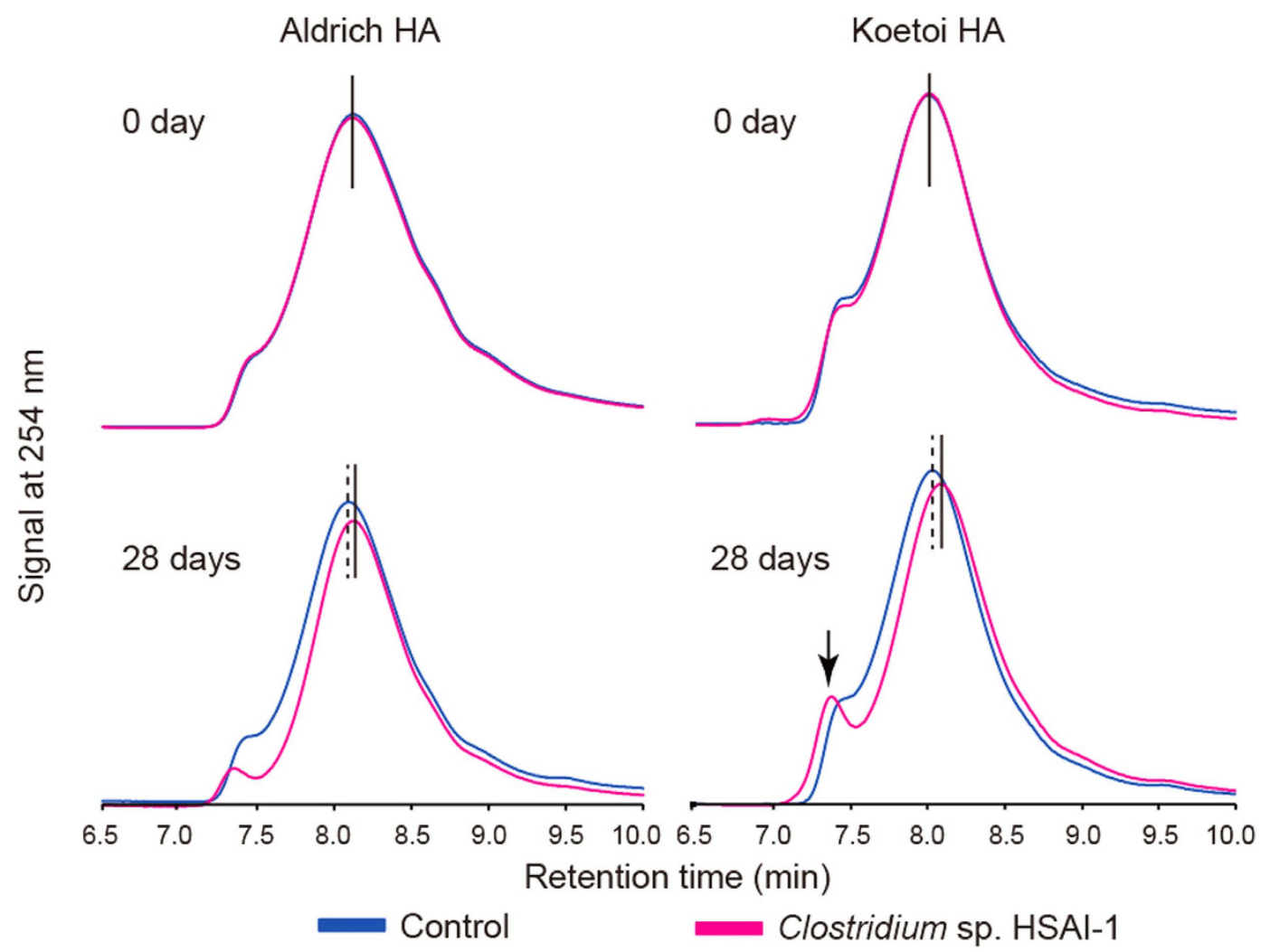

Figure 2. HSs are decomposed anaerobically by Clostridium sp. strain HSAI-1. Left column, chromatograms of Aldrich HAs at 0 and 28 days. Right column, chromatograms of Koetoi HAs at 0 and 28 days. Each experimental group consisted of 5 culture setups $(n=5)$. One representative chromatogram from each experimental group is shown. For clarity, chromatograms from uninoculated control cultures are depicted in blue, and those from inoculated cultures (using strain HSAI-1) are shown in magenta. The tops of the main peaks with retention times ranging from 7.8 to $8.3 \mathrm{~min}$ are indicated with vertical lines: a dotted line for the uninoculated controls and a solid line for the inoculated cultures. The peak indicated by the downward-pointing arrowhead corresponds to the high-molecular mass HAs in cultures inoculated with strain HSAI-1.

\begin{tabular}{|c|c|c|c|}
\hline & $\begin{array}{c}\text { Uninoculated } \\
\text { control (Da) }\end{array}$ & HSAI-1 (Da) & P-value \\
\hline Aldrich HA \\
\hline 0 day & $2790.1 \pm 15.5$ & $2801.4 \pm 12.7$ & 0.242 \\
\hline 28 days & $2887.3 \pm 12.9$ & $2673.1 \pm 76.8$ & $<0.001^{*}$ \\
\hline Koetoi HA \\
\hline 0 day & $3317.9 \pm 0.0$ & $3286.2 \pm 31.7$ & 0.056 \\
\hline 28 days & $3229.6 \pm 14.0$ & $2824.4 \pm 51.8$ & $<0.001^{*}$ \\
\hline
\end{tabular}

Table 2. Calculated molecular masses of the HA main peaks obtained from the HPSEC analysis. The table shows the mean values of the molecular masses with standard deviations calculated from the retention times obtained from the HPSEC analysis $(n=5)$. Molecular masses were calculated using the equation shown in Supplementary Fig. 4. *Significant differences were detected at 28 days between the uninoculated controls and the HSAI-1 inoculated cultures $(P<0.001)$.

the bands near 3410-3420 and $1710 \mathrm{~cm}^{-1}$ in both HAs and one near $1035 \mathrm{~cm}^{-1}$ in Koetoi HA; and 2) the appearance of four absorption bands near 3290-3300, 3070, 1540 and $1450 \mathrm{~cm}^{-1}$ in both HAs. The absorption bands near 2930, 1650 and $1230-1240 \mathrm{~cm}^{-1}$ were unchanged in both HAs. The absorption band near $3410-3420 \mathrm{~cm}^{-1}$ was assigned to $\mathrm{H}$-bonded $\mathrm{OH}$ groups, and the absorption band near $1710 \mathrm{~cm}^{-1}$ was assigned to $\mathrm{C}=\mathrm{O}$ stretching vibrations in carboxyls, aldehydes and ketones ${ }^{5}$. The absorption band near $1035 \mathrm{~cm}^{-1}$ in the Koetoi HAs was assigned to alcoholic and polysaccharide $\mathrm{C}-\mathrm{O}$ stretching vibrations and $\mathrm{OH}$ deformations ${ }^{6}$. These results suggest bacterial removal of carboxyl groups and polysaccharide-related moieties and the addition of aliphatic structural units, amide groups, and aromatic groups. 
Aldrich HAs

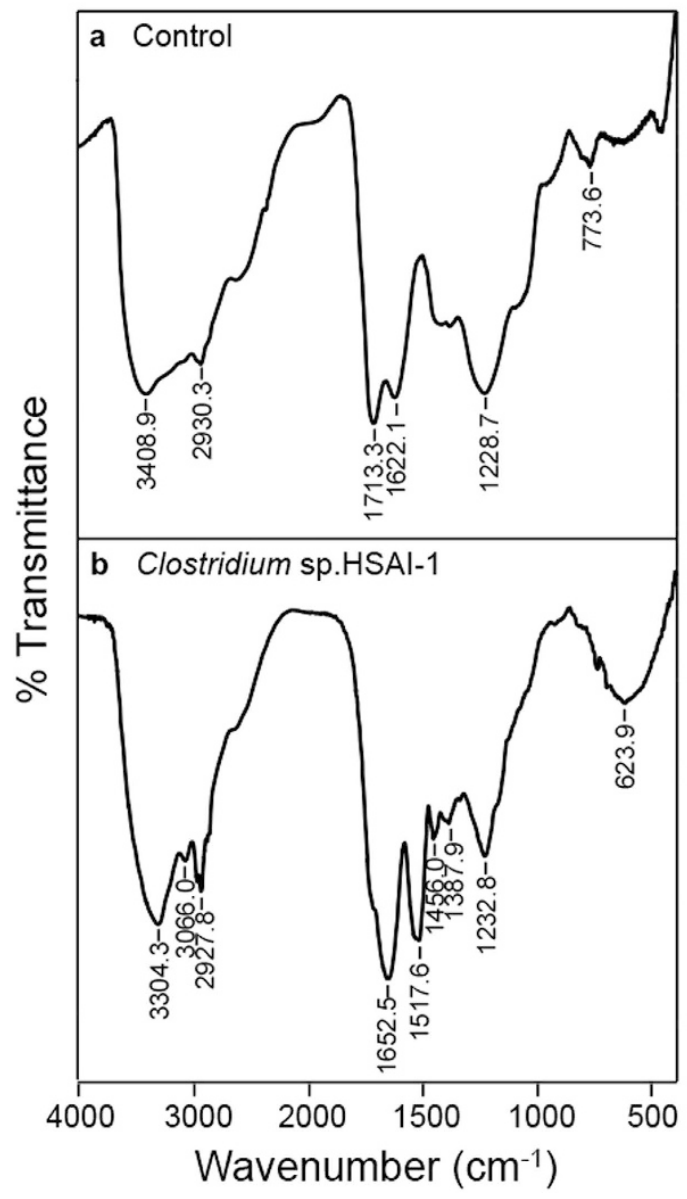

Koetoi HAs

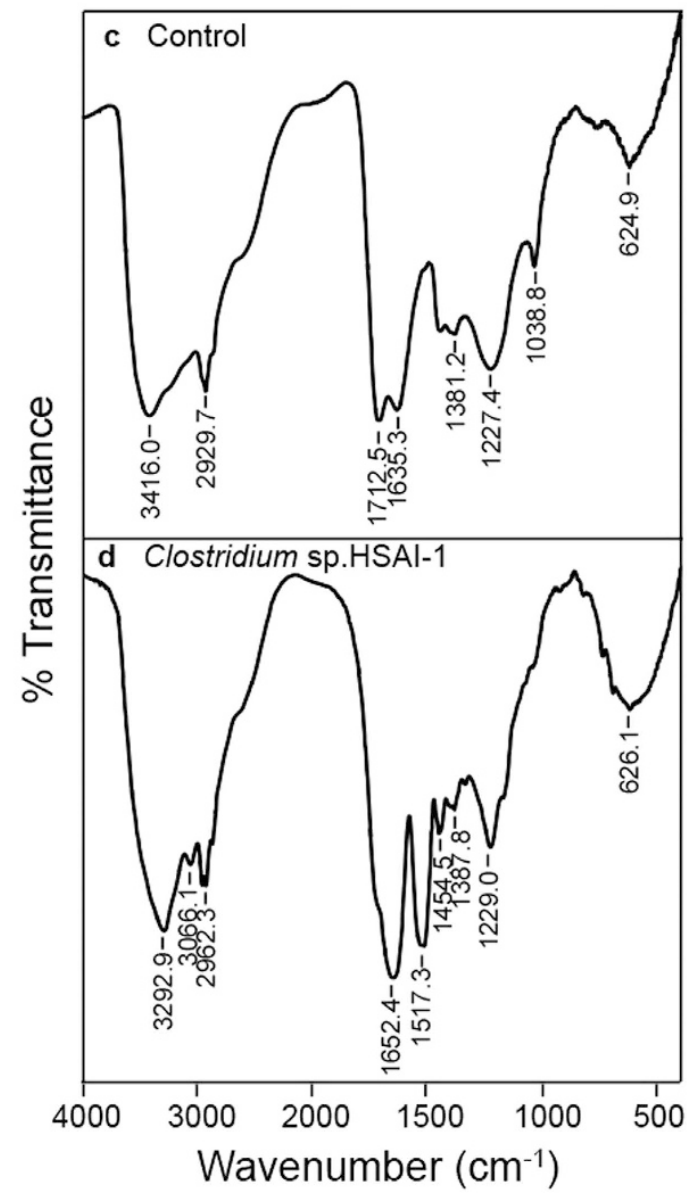

Figure 3. FT-IR spectra of HAs. Left column, Aldrich HAs. Right column, Koetoi HAs. Representative FT-IR spectra are shown for Aldrich HAs or Koetoi HAs $(n=3)$. $(\mathbf{a}, \mathbf{c})$ Uninoculated control cultures. (b,d) Cultures inoculated with Clostridium sp. strain HSAI-1.

\section{Discussion}

Our study suggests the possibility that HSs are microbially decomposed in the deep subsurface environment, where aerobic conditions are unlikely. Aerobic decomposition of HSs by microorganisms in the surface environment has been well documented ${ }^{4,7-12}$. However, the biogeochemical importance of the anaerobic decomposition of HSs remains poorly understood, although HSs are known to play an important role in the global carbon cycle ${ }^{13-16}$. Our results clearly showed that a single bacterial isolate under strictly anaerobic conditions can decompose HSs. Changes in HA structures during decomposition were previously observed in HA-containing fertilisers supplemented with steel slag as a source of soluble $\mathrm{Fe}(\mathrm{II})^{17}$. This previous study assumed the involvement of undefined sulfate-reducing bacteria, whereas our study focused on pure cultures of a Clostridium species.

Biopolymers, such as cellulose, lignocellulose and lignin, are major components of biomass in nature and account for approximately half of the matter produced by photosynthesis ${ }^{18}$. Clostridia can hydrolyse biopolymers, ferment monomers and amino acids, and produce alcohols, organic acids and hydrogen ${ }^{19}$. In particular, the best-studied anaerobic bacterium, C. thermocellum, hydrolyses lignocellulose to ferment the resulting sugars directly into ethanol ${ }^{20}$. Since strain HSAI-1 is classified into the genus Clostridium (Supplementary Fig. 1), this bacterial strain may be able to degrade biopolymers under anaerobic conditions in the context of the previously mentioned studies.

The deep terrestrial subsurface environment is generally thought to be oligotrophic. In this study, glucose supplementation facilitated the decomposition of HSs, and we demonstrated that strain HSAI-1 has potential to decompose HSs under anaerobic conditions. This setting would be unlikely in the deep subsurface environment; however, a recent theory has proposed that soil organic carbon in deep soil layers that has escaped microbial degradation and remained as ancient organic carbon for more than several thousand years could be subject again to degradation by microorganisms if an appropriate fresh organic carbon such as cellulose were to be supplied ${ }^{21}$. If anaerobic bacteria are stimulated by assimilable organic carbon existing in the subsurface environment, then the decomposition of HSs might occur in the deep subsurface environment. 
Historically, HSs have been operationally defined as humic and fulvic acids and humin based on their solubility under acidic or alkaline conditions ${ }^{13}$. However, recent information has shown that HSs are a mixture of diverse and relatively low molecular mass components. Direct in situ observations have demonstrated the formation of such associations between relatively small molecules by hydrophobic interactions and hydrogen bonds ${ }^{22,23}$. Nevertheless, the fundamental molecular structure of HSs is assumed to be similar to lignin because lignin is a major parent material in the formation of $\mathrm{HSs}^{24}$. Colberg and Young identified degradation products of lignin in a methane-forming consortium ${ }^{25}$, and they also identified 10 monomeric compounds including phenylacetate, benzoate, catechol, 3-phenylpropionate, cinnamate, $p$-hydroxybenzoate, $p$-hydroxycinnamate, syringate, vanillate, ferulate, caffeinate and vanillin ${ }^{25}$. Therefore, the anaerobic degradation of HA by strain HSAI-1 might produce monoaromatic compounds as degradation products of the HAs. Determining the compounds that are produced after the decomposition of HAs will be the focus of a future study.

It is widely accepted that HSs act as terminal electron acceptors under anaerobic conditions ${ }^{26-31}$. Nevertheless, coupling of HS reduction and HS degradation (such as decrease in molecular mass) has not been experimentally manifested. In our study, glucose was added to the culture media as a second carbon source that is easy to assimilate to strain HSAI-1. Under this condition, HAs were assumed to be used as terminal electron acceptors in the presence of glucose. Although the HA reduction should be taken into account, we could not determine whether HA was utilized as an electron acceptor. Another possibility would be the degradation of HA caused by co-metabolism. The white rot fungus Phanerochaete chrysosporium is capable of degrading HAs with the addition of glucose; nevertheless, $P$. chrysosporium did not utilize HS as the sole carbon source ${ }^{32}$.

Difference of FT-IR spectral patters between the uninoculated control and the HSAI-1 inoculated culture clearly demonstrated the decomposition of HA. Especially, the disappearance of the bands near $1710 \mathrm{~cm}^{-1}$ in both HAs and $1035 \mathrm{~cm}^{-1}$ in the Koetoi HAs was consistent with the result of a previous study in which the $\mathrm{C}=\mathrm{O}$ stretch from $\mathrm{COOH}$ at $1711 \mathrm{~cm}^{-1}$ and the polysaccharide-related IR band at $1033 \mathrm{~cm}^{-1}$ disappeared from the spectrum almost completely because of microbial degradation ${ }^{33,34}$. Our results also showed that ${ }^{14} \mathrm{CO}_{2}$ was released into the headspace during incubation when ${ }^{14} \mathrm{C}$-labelled polycatechol was used as substrate (Fig. 1 and Table 1). Taken together, these results indicated that carboxyl groups in both the Aldrich and Koetoi HAs and alcohol or polysaccharide-related substances in the Koetoi HAs are decomposed by strain HSAI-1, and $\mathrm{CO}_{2}$ is released, thus supporting the possibility of HA decomposition.

Previous studies revealed that lignolytic fungi degrade HAs concomitantly with the increasing amount of insoluble HAs in fungal cultures, which are not extractable with $\mathrm{NaOH}^{7,8}$. The authors suggested that the fungi not only degrade HAs but also produce refractory humin ${ }^{8}$. Some of the insoluble fraction in experiments inoculated with HSAI-1 may have been incorporated into biomass or closely bound to the cell surface, thus forming the refractory humic fraction. The production of acid-precipitable polymeric lignin with a molecular mass of $>20 \mathrm{kDa}$ during lignin degradation by $S$. viridosporus has been previously reported ${ }^{35}$. Similar substances may have also been produced in our Clostridium cultures.

In conclusion, we confirmed the decomposition of HSs by pure cultures of a strictly anaerobic bacterium isolated from the deep terrestrial subsurface. This finding conflicts with the previously reported decomposition of lignin, an HS component, by mixed cultures of soil microorganisms ${ }^{36,37}$. We supplemented the cultures with glucose to facilitate HS decomposition based on the hypothesis that supplies of fresh carbon may induce the microbial decomposition of organics that are stable over the long term in deep soil ${ }^{21}$. With this new knowledge, the biodegradation of persistent organic matter in the deep subsurface can be better defined, predicted and controlled.

\section{Methods}

Chemicals and bacterial strains. Aldrich humic acids (Aldrich HAs), in the form of humic acid sodium salt, were purchased from Sigma-Aldrich (St. Louis, MO, USA). HA-degrading S. viridosporus ATCC 39115 was purchased from ATCC (American-Type Culture Collection, Manassas, VA, USA) and was used as the reference strain $^{16}$. Clostridium sp. strain HSAI-1 was deposited at DSMZ (Deutsche Sammlung von Mikroorganismen und Zellkulturen GmbH, Braunschweig, Germany) and NBRC (NITE Biological Resource Center, National Institute of Technology and Evaluation, Kisarazu, Japan) under the accession numbers of DSM 100957 and NBRC 111506, respectively.

Sample collection. Groundwater samples were collected independently from three sites: the Horonobe deep borehole (HDB) in the Horonobe Underground Research Laboratory, the Yubari coal-bed methane recovery site, and a gas-petroleum reservoir in Higashi-Niigata, Japan (where mesothermic production water was collected). The geological features and the characteristics of archaeal and bacterial community structures in those areas were described previously ${ }^{38-40}$. The samples were stored in sterilised 1-L polypropylene bottles and transferred immediately to our laboratory. The mixture of groundwater collected from the three sites was used for the enrichment and cultivation of methanogens. After several transfers, an aliquot of the enriched culture was used as the inoculum for the enrichment and cultivation of HA-degrading bacteria. Siliceous mudstone samples were collected from the Koetoi Formation, which is composed of diatomite from the Miocene to Pliocene epochs, and used for preparing HAs as described below.

Preparation and extraction of HAs. The preparation of Aldrich and Koetoi HAs and HA extraction from culture media were performed according to the methods described by the International Humic Substances Society ${ }^{41}$. Throughout the study, HA-containing solutions were filter-sterilised using membrane filtration units (pore size $0.22 \mu \mathrm{m}$ ) before addition to culture media.

Media preparation and culturing techniques. The LPB culture medium was prepared with a slight modification in Hungate tubes (Chemglass Life Sciences, Vineland, NJ, USA) and was used as a basal liquid 
medium for the enrichment, isolation and maintenance of HSAI- $1^{42}$. The medium contained the following (per litre of distilled water): $\mathrm{KCl}, 0.1 \mathrm{~g} ; \mathrm{MgSO}_{4} \bullet 7 \mathrm{H}_{2} \mathrm{O}, 4.0 \mathrm{~g} ; \mathrm{NH}_{4} \mathrm{Cl}, 0.5 \mathrm{~g} ; \mathrm{CaCl}_{2} \bullet 2 \mathrm{H}_{2} \mathrm{O}, 0.14 \mathrm{~g} ; \mathrm{K}_{2} \mathrm{HPO}_{4}, 0.14 \mathrm{~g}$; $\mathrm{NaCl}, 6.0 \mathrm{~g} ; \mathrm{Fe}\left(\mathrm{NH}_{4}\right)_{2}\left(\mathrm{SO}_{4}\right)_{2} \bullet 6 \mathrm{H}_{2} \mathrm{O}, 2 \mathrm{mg} ; \mathrm{NaHCO}_{3}, 2.5 \mathrm{~g}$; Resazurin, $1.0 \mathrm{mg}$; Wolfe's vitamin solution, $10 \mathrm{ml}$; and trace metal solution, $10 \mathrm{ml}$. Wolfe's vitamin solution contained the following (per litre of distilled water): Biotin, $2.0 \mathrm{mg}$; Folic acid, $2.0 \mathrm{mg}$; Pyridoxine- $\mathrm{HCl}, 10.0 \mathrm{mg}$; Thiamine- $\mathrm{HCl} \cdot 2 \mathrm{H}_{2} \mathrm{O}, 5.0 \mathrm{mg}$; Riboflavin, $5.0 \mathrm{mg}$; Nicotinic acid, $5.0 \mathrm{mg}$; D-Ca-pantothenate, $5.0 \mathrm{mg}$; Vitamin $\mathrm{B}_{12}, 0.1 \mathrm{mg}$; -Aminobenzoic acid, $5.0 \mathrm{mg}$; and Lipoic acid, $5.0 \mathrm{mg}$. The trace metal solution contained the following (per litre of distilled water): Nitrilotriacetic acid, 1.5 g; $\mathrm{MgSO}_{4} \bullet 7 \mathrm{H}_{2} \mathrm{O}, 3 \mathrm{~g} ; \mathrm{MnSO}_{4} \bullet \mathrm{xH}_{2} \mathrm{O}, 0.5 \mathrm{~g} ; \mathrm{NaCl}, 1.0 \mathrm{~g} ; \mathrm{FeSO}_{4} \bullet 7 \mathrm{H}_{2} \mathrm{O}, 0.1 \mathrm{~g} ; \mathrm{CoSO}_{4} \bullet 7 \mathrm{H}_{2} \mathrm{O}, 0.1 \mathrm{~g} ; \mathrm{CaCl}_{2} \bullet 2 \mathrm{H}_{2} \mathrm{O}$, $0.1 \mathrm{~g} ; \mathrm{ZnSO}_{4} \bullet 7 \mathrm{H}_{2} \mathrm{O}, 0.1 \mathrm{~g} ; \mathrm{CuSO}_{4} \bullet 5 \mathrm{H}_{2} \mathrm{O}, 0.01 \mathrm{~g} ; \mathrm{AlK}\left(\mathrm{SO}_{4}\right)_{2}, 0.01 \mathrm{~g} ; \mathrm{H}_{3} \mathrm{BO}_{3}, 0.01 \mathrm{~g} ; \mathrm{Na}_{2} \mathrm{MoO}_{4} \bullet 2 \mathrm{H}_{2} \mathrm{O}, 0.01 \mathrm{~g}$; $\mathrm{NiCl}_{2} \bullet 6 \mathrm{H}_{2} \mathrm{O}, 0.025 \mathrm{~g} ; \mathrm{Na}_{2} \mathrm{SeO}_{3} \bullet 5 \mathrm{H}_{2} \mathrm{O}, 0.3 \mathrm{~g} ;\left(\mathrm{NH}_{4}\right)_{2} \mathrm{Ni}\left(\mathrm{SO}_{4}\right)_{2} \bullet 6 \mathrm{H}_{2} \mathrm{O}, 2 \mathrm{~g} ;$ and $\mathrm{Na}_{2} \mathrm{WO}_{4} \bullet 2 \mathrm{H}_{2} \mathrm{O}, 10 \mathrm{mg}$. Headspace gas was exchanged with anoxic $\mathrm{N}_{2}: \mathrm{CO}_{2}(80: 20, \mathrm{v} / \mathrm{v})$. After sterilisation, the following ingredients were added after filtration: $\mathrm{L}$-cysteine- $\mathrm{HCl} \cdot \mathrm{H}_{2} \mathrm{O}(0.05 \%, \mathrm{w} / \mathrm{v}) ; \mathrm{Na}_{2} \mathrm{~S} \bullet 9 \mathrm{H}_{2} \mathrm{O}(0.05 \%, \mathrm{w} / \mathrm{v})$; glucose $(0.5 \%$, w/v). When required, $20 \mathrm{mM}$ sodium-potassium phosphate ( $\mathrm{Na}-\mathrm{K}$-phosphate) buffer was added to the culture medium to adjust the $\mathrm{pH}$ to nearly neutral. All cultures were incubated at $30^{\circ} \mathrm{C}$ using previously described anaerobic techniques ${ }^{43}$. Bacterial isolation was performed on slant medium prepared in Hungate tubes under anaerobic conditions. The growth of the bacterial isolate was monitored by cell density, as determined by acridine orange staining described below $^{44}$. In all experiments of the decomposition of HAs, the culture medium was supplemented with $0.5 \%$ glucose because HSAI- 1 could not grow in media supplemented with HAs as the sole carbon source and required glucose as an auxiliary carbon source (Extended data Table 1).

Acridine orange $(\mathrm{AO})$ direct counting. AO direct counting was used to count bacteria in culture media under a fluorescence microscope ${ }^{44}$. The $\mathrm{AO}$ stock solution was prepared by dissolving $100 \mathrm{mg}$ of AO powder (Merck Millipore Co., Germany) in $10 \mathrm{ml}$ of sterile deionized water (1\%, w/v); this stock solution was protected from light and stored at $4{ }^{\circ} \mathrm{C}$. The working solution was prepared by diluting the AO stock solution in $10 \mathrm{mM}$ Tris- $\mathrm{HCl}$ ( $\mathrm{pH} 7.2$ ) to a final concentration of $0.01 \%$. The AO working solution and $1 \times$ phosphate-buffered saline (PBS) were filter sterilized using a $0.22 \mu \mathrm{m}$ filter unit (Sartorius, Göttingen, Germany) before use. At each sampling time, a $1 \mathrm{ml}$ sample of each culture medium was obtained using sterilized syringes. Samples containing bacteria were fixed in formalin and then stored at $4{ }^{\circ} \mathrm{C}$ overnight. Fixed samples were diluted with $1 \times \mathrm{PBS}$ as appropriate and passed through an Isopore membrane filter (pore size $0.22 \mu \mathrm{m}$, diameter $47 \mathrm{~mm}$, type GSWP 04700, Millipore, Billerica, MA, USA) to trap bacteria using a vacuum filter unit (SPC filter holders, Shibata Scientific Technology, Ltd., Japan). Bacteria were stained by applying AO solution to the membrane at room temperature in the dark for $3 \mathrm{~min}$. Subsequently, the AO solution was drained by vacuum, and the membrane was rinsed once with $1 \times$ PBS. The membrane filter was sandwiched between a slide and a cover glass. Using epifluorescence microscopy (Olympus BX-51), bacterial cells were enumerated at $1000 \times$ under oil immersion in at least 20-40 randomly chosen microscope fields in triplicate for each sample. The total cell count in each sample was calculated by applying the formula (equation 1$)^{45}$ :

$$
\frac{[(\text { mean value of cell count per field }) /(\text { field area })] \times(\text { dispersed area })}{\text { sample volume }} \times \text { dilution factor }
$$

where "field area", which was $0.012 \pi \mathrm{mm}^{2}$ in our study, was calculated by dividing the field number (FN) by the magnification of the objective $(100 \times)$; "dispersed area" was the effective size of the region over which the sample was dispersed (i.e., the area of the stained region on the Isopore membrane filter, which was $64 \pi \mathrm{mm}^{2}$ in our study); "sample volume" was the volume of bacterial sample applied to the Isopore membrane filter for staining; and "dilution factor" represented the degree to which the formalin-fixed bacterial sample was diluted with $1 \times$ PBS.

Nucleic acid-based analyses. Genomic DNA of the bacterial isolate was extracted using the Microbial DNA Isolation Kit (MoBio Laboratories, Inc., Carlsbad, CA, USA) according to the manufacturer's protocol. Subsequently, near full-length $16 \mathrm{~S}$ rRNA gene fragments (approximately $1,400 \mathrm{bp}$ ) were produced by PCR amplification using the universal bacterial primers $27 \mathrm{~F}\left(5^{\prime}\right.$-AGAGTTTGATCCTGGCTCAG-3') corresponding to position 8-27 of E. coli and 1492R (5' -GGTTACCTTGTTACGACTT-3') corresponding to position 1510-1492 of E. coli $^{46}$. PCR was performed using a PTC-200 DNA Engine Gradient Cycler (MJ Research Science, USA) in a total volume of $20 \mu \mathrm{L}$ using TaKaRa Ex Taq DNA polymerase (TaKaRa Shuzo, Shiga, Japan) in the supplied buffer. The following thermal cycling program was used: initial denaturation at $95^{\circ} \mathrm{C}$ for $5 \mathrm{~min} ; 30$ cycles each of denaturation at $95^{\circ} \mathrm{C}$ for $30 \mathrm{sec}$, annealing at $55^{\circ} \mathrm{C}$ for $30 \mathrm{sec}$, and extension at $72^{\circ} \mathrm{C}$ for $2 \mathrm{~min}$; followed by a final extension at $72^{\circ} \mathrm{C}$ for $5 \mathrm{~min}$. Negative controls without DNA template were run for all samples. The PCR products were purified using a QIAquick PCR Purification Kit (Qiagen) and then analysed by SolGent ${ }^{\mathrm{TM}}$ Sequencing Service (SolGent Co., Ltd.). The identification of phylogenetic neighbours was carried out by comparing data in the EzTaxon-e program against the database containing strain types with verifiable, published prokaryotic names and representatives of uncultured phylotypes, which was implemented at the EzTaxon-e server ${ }^{47}$. A phylogenetic tree was constructed in MEGA 5.2.2 based on the neighbour-joining method ${ }^{48,49}$.

Synthesis of ${ }^{14} \mathrm{C}$-HA. $\quad{ }^{14} \mathrm{C}$-Labelled polycatechol $\left({ }^{14} \mathrm{C}-\mathrm{HA}\right)$, which is an HA-analogue, was synthesised by spontaneous oxidative polymerisation of $\left[\mathrm{U}_{-}{ }^{14} \mathrm{C}\right]$ catechol (specific radioactivity, $1.48-1.85 \mathrm{GBq} \mathrm{mmol}^{-1}$; radi-

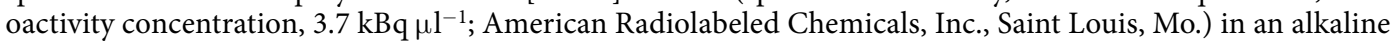
solution ${ }^{5}$. [U- $\left.{ }^{14} \mathrm{C}\right]$ catechol $\left(1,776 \mathrm{kBq} ; 1.07 \times 10^{8} \mathrm{dpm}\right)$ and $11 \mathrm{mg}$ of unlabelled catechol were dissolved in $1 \mathrm{ml}$ of $\mathrm{NaOH}\left(0.1 \mathrm{~N}\right.$ ), which also contained $\mathrm{Mn}^{2+}$ (final concentration, $2 \mathrm{mM}$ ) to enhance the polymerisation process $^{50}$. The reaction mixture was incubated with vigorous stirring at room temperature overnight. ${ }^{14} \mathrm{C}-\mathrm{HA}$ was precipitated by the addition of $50 \mu \mathrm{l}$ of $6 \mathrm{~N} \mathrm{HCl}$, followed by centrifugation. The ${ }^{14} \mathrm{C}-\mathrm{HA}$ pellet was rinsed with 
distilled water up to eight times, after which the residual radioactivity level in the supernatant was low and stable (Supplementary Fig. 2). The resulting ${ }^{14} \mathrm{C}$-HA pellet was re-suspended in $1 \mathrm{ml}$ of $0.1 \mathrm{~N} \mathrm{NaOH}$ with a radioactivity of $0.12 \times 10^{6} \mathrm{dpm}$, which contained approximately $0.11 \%$ of the original ${ }^{14} \mathrm{C}$-labelled catechol.

Decomposition experiments with radioactive HA. Decomposition experiments using ${ }^{14} \mathrm{C}$-HA were performed in $3 \mathrm{ml}$ of basal liquid media, as described above, under anaerobic conditions. ${ }^{14} \mathrm{C}$-HA with a radioactivity level of $1,215 \mathrm{dpm}$ was added to each medium, as well as $500 \mu \mathrm{l}$ of HSAI-1 pre-grown for 7 days. In uninoculated controls, $500 \mu \mathrm{l}$ of filter-sterilised culture medium containing HSAI-1 was added. Incubation was carried out at $30^{\circ} \mathrm{C}$ in the dark. During incubation, $500 \mu \mathrm{l}$ of headspace gas was obtained using a gas-tight syringe and passed through $2 \mathrm{ml}$ of Carbo-Sorb E (Perkin Elmer Inc.; Waltham, MA, USA), followed by the addition of $2 \mathrm{ml}$ of Permafluor E + (Perkin Elmer Inc.; Waltham, MA, USA) for ${ }^{14} \mathrm{CO}_{2}$, and $4 \mathrm{ml}$ of Clearsol I (Nakarai Tesque, Kyoto, Japan) for ${ }^{14} \mathrm{C}$-labelled volatile compounds. After 7 weeks of incubation, ${ }^{14} \mathrm{C}-\mathrm{HA}$ was dissolved by adding $500 \mu \mathrm{l}$ of $10 \mathrm{~N} \mathrm{NaOH}$ to the culture media, followed by vigorous shaking. After centrifugation, $500 \mu \mathrm{l}$ of supernatant was used to determine the soluble radioactivity $\left({ }^{14} \mathrm{C}\right.$-labelled $\mathrm{NaOH}$-soluble material). The whole pellet after centrifugation was used to determine the insoluble radioactivity (residual ${ }^{14} \mathrm{C}$ ). A liquid scintillation counter (model LSC-6100; Aloka) was used for radioactivity measurements. Percent mineralisation was calculated after subtracting background counts in the negative controls using the following equation (eq. 2):

$$
\text { Decomposition }[\%]=\frac{{ }^{*} \text { Radioactivity of }{ }^{14} \mathrm{CO}_{2} \text { in the whole part of headspace }(\mathrm{dpm})}{\text { Radioactivity of }{ }^{14} \mathrm{C}-\mathrm{HA} \text { in culture medium }(1,215 \mathrm{dpm})} \times 100
$$

${ }^{*}$ Radioactivity of ${ }^{14} \mathrm{CO}_{2}$ in the whole part of headspace $(13.6 \mathrm{~mL})=$ Radioactivity of ${ }^{14} \mathrm{CO}_{2}$ in $500 \mu \mathrm{l} \times 27.2$.

Extraction of HA from culture media. HA was extracted from the culture media according to a previously defined $\operatorname{method}^{7}$ with slight modification. Culture media were centrifuged at $20,000 \times g$ for 30 min to separate the culture supernatant and cell debris, and then the culture supernatant was transferred to new test tubes. Subsequently, $10 \mathrm{~N} \mathrm{NaOH}$ was added to the culture supernatant to increase the alkalinity of the solution $(>\mathrm{pH}$ 12.0) to dissolve the HA completely, and the samples were shaken vigorously on a reciprocal shaker (Type MK201D; Yamato Scientific Co. Ltd., Japan) overnight. The samples were centrifuged at 20,000 $\times g$ for 20 min to separate the insoluble fraction and supernatant. The resulting supernatant was mixed with $6 \mathrm{~N} \mathrm{HCl}$ to increase the acidity of the solution $(<\mathrm{pH} 2.0)$ to precipitate the acid-insoluble HAs. After centrifugation at 20,000 $\times g$ for $20 \mathrm{~min}$, the HA precipitate was rinsed twice with $0.1 \mathrm{~N} \mathrm{HCl}$ and then once with water. Finally, the rinsed HA precipitate was lyophilized under vacuum overnight. The dried HAs were stored at $-20^{\circ} \mathrm{C}$ until use.

Instrumental analyses of HAs. Prior to the instrumental analyses, HAs were extracted from culture media as described above. HPSEC analysis was conducted using a Prominence HPLC (SPD-M20A, Shimadzu, Kyoto, Japan) equipped with a photodiode array detector and a GL-W530 column (Hitachi Hitec, Japan; 10.7 mm I.D. by $300 \mathrm{~mm}$ ) preceded by a guard column (Hitachi Hitec; $4.0 \mathrm{~mm}$ I.D. by $10 \mathrm{~mm}$ ). According to the manufacturer's catalogue, the approximate upper exclusion limit was 50,000 $\mathrm{Da}$ (calibrated with pullulan). Isocratic elution with a mobile phase mixture of $10 \mathrm{mM}$ Tris- $\mathrm{HCl}(\mathrm{pH} 8.0)$ and $10 \mathrm{mM} \mathrm{NaCl}$ was performed at a flow rate of $1.0 \mathrm{~mL} \mathrm{~min}^{-1}$ at a constant temperature of $40^{\circ} \mathrm{C}$. The column was calibrated using sodium polystyrene sulfonates $(1.3-168 \mathrm{kDa})$. Elution profiles were recorded, and the resulting data were reanalysed with LC Solution software (Shimadzu, Kyoto, Japan). FT-IR analysis was carried out by the Osaka Kankyo Gijutsu Center Co., Ltd. (Osaka, Japan). FT-IR spectra were measured with a Nicolet iS10 FT-IR spectrometer (Thermo Fisher Scientific Inc., USA.) scanning the $4000-400 \mathrm{~cm}^{-1}$ range with an average of 128 scans and a spectral resolution of $4 \mathrm{~cm}^{-1}$.

Statistical analysis. Statistical comparisons between the control and test groups were performed using Student's $t$-test. Differences were considered significant at $P<0.05$.

\section{References}

1. Sundquist, E. T. \& Visser, K. The Geologic History of the Carbon Cycle in Treatise on Geochemistry 2nd edn, (eds Heinrich D. Holland \& Karl K. Turekian) 361-398 (Pergamon, 2014).

2. Ishiwatari, R. Geochemistry of Humic Substances in Lake Sediments. in Humic Substances in Soil, Sediment, and Water. (eds Aiken, G. R. et al.) 147-180 (John Wiley \& Sons, 1985).

3. Ueno, A. et al. Structural alteration of humic acids by Pseudomonas spp. from deep terrestrial subsurface diatomite formations in northernmost Japan. Geomicrobiol. J. 31, 654-663 (2014).

4. Kontchou, C. Y. \& Blondeau, R. Biodegradation of soil humic acids by Streptomyces viridosporus. Can. J. Microbiol. 38, 203-208 (1992).

5. Yonebayashi, K. \& Hattori, T. Chemical and biological studies on environmental humic acids II. ${ }^{1} \mathrm{H}$-nmr and IR spectra of humic acids. Soil Sci. Plant Nutr. 35, 383-392 (1989).

6. Sakellariadou, F. Spectroscopic studies of humic acids from subsurface sediment samples collected across the Aegean Sea. Medit. Mar. Sci. 7, 11-17 (2006).

7. Steffen, K. T., Hatakka, A. \& Hofrichter, M. Degradation of humic acids by the litter-decomposing basidiomycete Collybia dryophila. Appl. Environ. Microbiol. 68, 3442-3448 (2002).

8. Kluczek-Turpeinen, B., Steffen, K. T., Tuomela, M., Hatakka, A. \& Hofrichter, M. Modification of humic acids by the compost-dwelling deuteromycete Paecilomyces inflatus. Appl. Microbiol. Biotechnol. 66, 443-449 (2005).

9. Dari, K., Béchet, M. \& Blondeau, R. Isolation of soil Streptomyces strains capable of degrading humic acids and analysis of their peroxidase activity. FEMS Microbiol. Ecol. 16, 115-122 (1995).

10. Hurst, H. M., Burges, A. \& Latter, P. Some aspects of the biochemistry of humic acid decomposition by fungi. Phytochemistry 1, 227-231 (1962).

11. Mathur, S. P. \& Paul, E. A. Microbial utilization of soil humic acids. Can. J. Microbiol. 13, 573-580 (1967).

12. Yanagi, Y., Tamaki, H., Otsuka, H. \& Fujitake, N. Comparison of decolorization by microorganisms of humic acids with different ${ }^{13} \mathrm{C}$ NMR properties. Soil Biol. Biochem. 34, 729-731 (2002). 
13. Stevenson, F. J. In Humus chemistry: Genesis, Composition, Reactions. 2nd edn, Ch. 1, 1-23 (John Wiley, 1994).

14. Berner, R. A. The long-term carbon cycle, fossil fuels and atmospheric composition. Nature 426, 323-326 (2003).

15. Bleam, W. F. Natural Organic Matter and Humic Colloids in Soil and Environmental Chemistry (ed. Bleam, W. F.) Ch. 6, 209-256 (Academic Press, 2012).

16. Tan, K. H. Nature and Distribution of Humic Matter In Humic Matter in Soil and the Environment: Principles and Controversies. 2nd edn, (ed. Tan, K. H.) Ch. 4, 109-134 (CRC Press, 2014).

17. Fujisawa, N. et al. Structural alterations of humic acid fractions in a steel slag-compost fertilizer during fertilization. Analysis by pyrolysis/methylation-gas chromatography/mass spectrometry. J. Anal. Appl. Pyrol. 95, 126-133 (2012).

18. Pérez, J., Muñoz-Dorado, J., de la Rubia, T. \& Martínez, J. Biodegradation and biological treatments of cellulose, hemicellulose and lignin: an overview. Int. Microbiol. 5, 53-63 (2002).

19. Ivanov, V. Microbiology of Environmental Engineering Systems in Environmental Biotechnology. 1 edn, Vol. 10 (eds Wang et al.) 19-79 (Humana Press, 2010).

20. Akinosho, H., Yee, K., Close, D. \& Ragauskas, A. The emergence of Clostridium thermocellum as a high utility candidate for consolidated bioprocessing applications. Frontiers in chemistry 2, 66 (2014).

21. Fontaine, S. et al. Stability of organic carbon in deep soil layers controlled by fresh carbon supply. Nature 450, 277-280 (2007).

22. Sutton, R. \& Sposito, G. Molecular structure in soil humic substances: The new view. Environ. Sci. Technol. 39, 9009-9015 (2005).

23. Schmidt, M. W. et al. Persistence of soil organic matter as an ecosystem property. Nature 478, 49-56 (2011).

24. Senesi, N. \& Loffredo, E. Soil Humic Substances in Biopolymers (eds Steinbüchel A. \& Hofrichter M.) Ch. 9, 247-299 (Wiley-VCH, 2003).

25. Colberg, P. J. \& Young, L. Y. Aromatic and volatile acid intermediates observed during anaerobic metabolism of lignin-derived oligomers. Appl. Environ. Microbiol. 49, 350-358 (1985).

26. Scott, D. T., McKnight, D. M., Blunt-Harris, E. L., Kolesar, S. E. \& Lovley, D. R. Quinone moieties act as electron acceptors in the reduction of humic substances by humics-reducing microorganisms. Environ. Sci. Technol. 32, 2984-2989 (1998).

27. Aeschbacher, M., Sander, M. \& Schwarzenbach, R. P. Novel electrochemical approach to assess the redox properties of humic substances. Environ. Sci. Technol. 44, 87-93 (2010).

28. Lovley, D. R., Coates, J. D., Blunt-Harris, E. L., Phillips, E. J. \& Woodward, J. C. Humic substances as electron acceptors for microbial respiration. Nature 382, 445-448 (1996).

29. Roden, E. E. et al. Extracellular electron transfer through microbial reduction of solid-phase humic substances. Nature Geosci 3, 417-421 (2010)

30. Benz, M., Schink, B. \& Brune, A. Humic acid reduction by Propionibacterium freudenreichii and other fermenting bacteria. Appl. Environ. Microbiol. 64, 4507-4512 (1998).

31. Cervantes, F. J. et al. Anaerobic mineralization of toluene by enriched sediments with quinones and humus as terminal electron acceptors. Appl. Environ. Microbiol. 67, 4471-4478 (2001).

32. Blondeau, R. Biodegradation of natural and synthetic humic acids by the white rot fungus Phanerochaete chrysosporium. Appl. Environ. Microbiol. 55, 1282-1285 (1989).

33. Filip, Z. \& Tesařová, M. Microbial degradation and transformation of humic acids from permanent meadow and forest soils. Int. Biodeterior. Biodegrad. 54, 225-231 (2004).

34. Filip, Z. \& Berthelin, J. Analytical determination of the microbial utilization and transformation of humic acids extracted from municipal refuse. Fresenius J. Anal. Chem. 371, 675-681 (2001)

35. Crawford, D. L., Pometto, A. L. \& Crawford, R. L. Lignin degradation by Streptomyces viridosporus: isolation and characterization of a new polymeric lignin degradation intermediate. Appl. Environ. Microbiol. 45, 898-904 (1983).

36. Benner, R., Maccubbin, A. E. \& Hodson, R. E. Anaerobic biodegradation of the lignin and polysaccharide components of lignocellulose and synthetic lignin by sediment microflora. Appl. Environ. Microbiol. 47, 998-1004 (1984).

37. Colberg, P. J. \& Young, L. Y. Anaerobic degradation of soluble fractions of $\left[{ }^{14} \mathrm{C}\right.$-lignin $]$ lignocellulose. Appl. Environ. Microbiol. 49, 345-349 (1985)

38. Shimizu, S. et al. Molecular characterization of microbial communities in fault-bordered aquifers in the Miocene formation of northernmost Japan. Geobiology 4, 203-213 (2006).

39. Shimizu, S. et al. Molecular characterization of microbial communities in deep coal seam groundwater of northern Japan. Geobiology 5, 423-433 (2007).

40. Shimizu, S., Ueno, A. \& Ishijima, Y. Microbial communities associated with acetate-rich gas-petroleum reservoir surface facilities. Biosci. Biotechnol. Biochem. 75, 1835-1837 (2011).

41. Swift, R. S. Organic matter characterization in Methods of soil analysis Part 3. Chemical Methods (eds. Sparks, D. L. et al.) Ch. 35, 1018-1020 (Soil Sci. Soc. Am. Madison, WI, 1996).

42. Dianou, D. et al. Methanoculleus chikugoensis sp. nov., a novel methanogenic archaeon isolated from paddy field soil in Japan, and DNA-DNA hybridization among Methanoculleus species. Int. J. Syst. Evol. Microbiol. 51, 1663-1669 (2001).

43. Hungate, R. E. The anaerobic mesophilic cellulolytic bacteria. Bacteriol. Rev. 14, 1-49 (1950).

44. Kronvall, G. \& Myhre, E. Differential staining of bacteria in clinical specimens using acridine orange buffered at low pH. Acta Pathol. Microbiol. Scand. B 85, 249-254 (1977).

45. Franklin, R. B. et al. Enumerating bacterial cells on bioadhesive coated slides. J. Microbiol. Methods 87, 154-160 (2011).

46. Lane, D. J. 16S/23S rRNA sequencing. Nucleic Acid Techniques in Bacterial Systematics, 125-175 (1991).

47. Kim, O. S. et al. Introducing EzTaxon-e: a prokaryotic $16 \mathrm{~S}$ rRNA gene sequence database with phylotypes that represent uncultured species. Int. J. Syst. Evol. Microbiol. 62, 716-721 (2012).

48. Saitou, N. \& Nei, M. The neighbor-joining method: a new method for reconstructing phylogenetic trees. Mol. Biol. Evol. 4, 406-425 (1987).

49. Tamura, K. et al. MEGA5: molecular evolutionary genetics analysis using maximum likelihood, evolutionary distance, and maximum parsimony methods. Mol. Biol. Evol. 28, 2731-2739 (2011).

50. Jha, P. K. \& Halada, G. P. The catalytic role of uranyl in formation of polycatechol complexes. Chem. Cent. J. 5, 12 (2011).

\section{Acknowledgements}

This work was supported by the Ministry of the Economy, Trade and Industry (METI) of Japan. We would like to acknowledge the Japan Atomic Energy Agency (JAEA) for the collection of subsurface groundwater samples at the Horonobe Underground Research Laboratory. We are grateful to the Japan Petroleum Exploration Co., Ltd. and the Mitsubishi Gas Chemical Company, Inc. for their cooperation in sample collection. We gratefully thank the Central Institute of Isotope Science, Hokkaido University, for accommodating us with the facilities for the isotope experiments. We would also like to thank Dr. Masami Fukushima from the Graduate School of Engineering of Hokkaido University for technical advice regarding HA analysis. We appreciate the technical assistance provided by Mr. Hiroyuki Tada. 


\section{Author Contributions}

A.U. designed the study, performed the experiments, and wrote the manuscript with input from the other authors. S.S. collected groundwater samples, prepared an enrichment culture to isolate Clostridium sp. strain HSAI-1, and discussed the content of the present study. S.T. prepared natural Koetoi HAs. T.N. carefully read and edited the manuscript. H.O. and K.K. participated in discussions about the content of the study.

\section{Additional Information}

Supplementary information accompanies this paper at http://www.nature.com/srep

Competing financial interests: The authors declare no competing financial interests.

How to cite this article: Ueno, A. et al. Anaerobic decomposition of humic substances by Clostridium from the deep subsurface. Sci. Rep. 6, 18990; doi: 10.1038/srep18990 (2016).

(c) (i) This work is licensed under a Creative Commons Attribution 4.0 International License. The images or other third party material in this article are included in the article's Creative Commons license, unless indicated otherwise in the credit line; if the material is not included under the Creative Commons license, users will need to obtain permission from the license holder to reproduce the material. To view a copy of this license, visit http://creativecommons.org/licenses/by/4.0/ 